\title{
Kinetic analysis of GTP hydrolysis catalysed by the Arf1-GTP-ASAP1 complex
}

\author{
Ruibai LUO*, Bijan AHVAZI†, Diana AMARIEI*, Deborah SHRODER*, Beatriz BURROLA $\ddagger$, Wolfgang LOSERT $\ddagger$ \\ and Paul A. RANDAZZO*1 \\ *Laboratory of Cellular Oncology, Center for Cancer Research, National Cancer Institute, Bethesda, MD 20892, U.S.A., † National Institute of Arthritis and Musculoskeletal and Skin \\ Diseases, Bethesda, MD 20892, U.S.A., and $\ddagger$ Department of Physics and IPST (Institute for Physical Sciences and Technology), University of Maryland, College Park, MD 20742, U.S.A.
}

Arf (ADP-ribosylation factor) GAPs (GTPase-activating proteins) are enzymes that catalyse the hydrolysis of GTP bound to the small GTP-binding protein Arf. They have also been proposed to function as Arf effectors and oncogenes. We have set out to characterize the kinetics of the GAP-induced GTP hydrolysis using a truncated form of ASAP1 [Arf GAP with SH3 (Src homology 3) domain, ankyrin repeats and PH (pleckstrin homology) domains 1] as a model. We found that ASAP1 used Arf1-GTP as a substrate with a $k_{\text {cat }}$ of $57 \pm 5 \mathrm{~s}^{-1}$ and a $K_{\mathrm{m}}$ of $2.2 \pm 0.5 \mu \mathrm{M}$ determined by steady-state kinetics and a $k_{\text {cat }}$ of $56 \pm 7 \mathrm{~s}^{-1}$ determined by single-turnover kinetics. Tetrafluoroaluminate $\left(\mathrm{AlF}_{4}{ }^{-}\right)$, which stabilizes complexes of other Ras family members with their cognate GAPs, also stabilized a complex of Arf1-GDP with ASAP1. As anticipated, mutation of Arg-497 to a lysine residue affected $k_{\text {cat }}$ to a much greater extent than $K_{\mathrm{m}}$. Changing Trp-479, Iso-490, Arg-505, Leu-511 or Asp-512 was predicted, based on previous studies, to affect affinity for Arf1-GTP. Instead, these mutations primarily affected the $k_{\text {cat }}$. Mutants that lacked activity in vitro similarly lacked activity in an in vivo assay of ASAP1 function, the inhibition of dorsal ruffle formation. Our results support the conclusion that the Arf GAP ASAP1 functions in binary complex with Arf1-GTP to induce a transition state towards GTP hydrolysis. The results have led us to speculate that Arf1-GTP-ASAP1 undergoes a significant conformational change when transitioning from the ground to catalytically active state. The ramifications for the putative effector function of ASAP1 are discussed.

Key words: Arf GAP with SH3, ankyrin repeats and PH domains 1 (ASAP1), ADP-ribosylation factor (Arf), GTPase-activating protein (GAP), GTP-binding protein, GTP hydrolysis, kinetics.

\section{INTRODUCTION}

Arf (ADP-ribosylation factor) GAPs (GTPase-activating proteins) are a family of proteins first identified on the basis of their ability to induce the hydrolysis of GTP bound to Arf proteins [1-3]. The catalytic domain was found to comprise a zinc-binding motif [2]. At least 24 genes encode proteins predicted to be Arf GAPs based on homology (for reviews see [3-5]). Seventeen proteins have demonstrated activity. These proteins can be categorized into six groups based on unique domain structures: Arf GAP1/3, Git1/2 (protein interacting with G-protein-coupled-receptor kinase), ASAP1/2/3 [Arf GAP with SH3 (Src homology 3) domain, ANKs (ankyrin repeats) and $\mathrm{PH}$ (pleckstrin homology) domains 1, 2 and 3), ARAP1/2/3 (Arf GAP with Rho GAP, ANKs and PH domains), ACAP1/2/3 (Arf GAP with coiled-coil domains, ANKs and PH domains 1,2 and 3) and AGAP1/2/3 (Arf GAP with GTP-bindingprotein-like, ANKs and pleckstrin homology domains 1, 2 and 3). Consistent with their interaction with Arf proteins, the Arf GAPs regulate membrane traffic and the actin cytoskeleton. In addition, the Arf GAPs have been implicated in processes independent of Arf [6,7], as Arf effectors [8-10] and potentially as oncogenes [11].

The substrates of the Arf GAPs are Arf GTP-binding proteins (reviewed in [12-14]). The Arf proteins are part of the Arf family of GTP-binding proteins. Six Arf proteins have been identified in mammals, five in humans. The most extensively studied are Arf1 and Arf6, which regulate membrane traffic and actin remodelling. The cellular function of Arf1 and Arf6 depends on binding and hydrolysis of GTP [14-16]. Since Arf has no intrinsic GTPase activity, Arf GAPs are critical to Arf function.

Arf GAPs may also function as Arf effectors. Arf GAP1, for instance, has been found to be necessary for formation of transport vesicles [9]. AGAP1 and AGAP2 have been found to function as components of clathrin/AP-3 (activator protein 3) and clathrin/AP-1 (activator protein 1) coats [17,18]. ASAP1 may also be an Arf effector [10]. It has been found to bend membranes, an important step in the formation of membrane transport intermediates. ASAP1-induced membrane bending is dependent on the acid phospholipid content of the membrane and Arf1-GTP.

To understand how GTP hydrolysis is regulated, the structural determinants of GAP activity have been examined [19-21]. Some work, based on a combination of crystallography and biochemical studies with truncated proteins $[19,20]$, supports the idea that Arf GAP1 functions in a three part complex with coat protein and Arf1-GTP. Switch 1 does not interact with the GAP in this model. Switch 2 of Arf1 interacts with helices $\alpha \mathrm{C}$ and $\alpha \mathrm{F}$ of Arf GAP1. A second surface of interaction is strand $\beta 5$ and adjacent loop of Arf GAP1 with the $\alpha 3$ helix of Arf-GTP. All residues from Arf GAP are greater than $15 \AA(1 \AA=0.1 \mathrm{~nm})$ from the active site, which was part of the basis for the conclusion that the coat protein contributes a catalytic residue to the active site. This model is not supported by other studies. For instance, Arf-GTP could productively interact with Arf GAP1 in binary complex with little effect of coatomer when a model membrane was present [22]. In addition, mutagenesis studies implicate switch 1 in the interaction with ASAP1, Arf GAP1 and AGAP1 [23,24]. The model

Abbreviations used: ANK, ankyrin repeat; Arf, ADP-ribosylation factor; ASAP, Arf GAP with SH3 (Src homology 3), ANKs and PH domains; DTT, dithiothreitol; GAP, GTPase-activating protein; GST, glutathione S-transferase; HA, haemagglutinin; LUVs, large unilamellar vesicles; myrArf1, myristoylated Arf1; PAP, phosphatidic acid phosphohydrolase; PDGF, platelet-derived growth factor; PH domain, pleckstrin homology domain.

1 To whom correspondence should be addressed (email randazzo@helix.nih.gov). 
developed for Arf GAP1 does not appear to extrapolate to other Arf GAPs [21]. In a structural model of PAP (phosphatidic acid phosphohydrolase), the ANK domains of PAP interface with the same surface of the Arf GAP domain that binds Arf in the Arf GAP1 structure. Based on the structural model of PAP, Mandiyan et al. [21] proposed a different Arf1-GTP binding site involving a number of amino acid side chains on the surface of the GAP domain and surrounding a presumed catalytic arginine residue.

Here, we kinetically characterize ASAP1, a close homologue of PAP. On the basis of mutagenesis and a combination of pre-steadystate and steady-state kinetics, we found that ASAP1 functions in binary complex with Arf1-GTP, consistent with the conclusions based on the crystal structure of PAP. However, mutation of residues thought to affect Arf binding did not affect the affinity or $K_{\mathrm{m}}$ for Arf1-GTP but instead affected the catalytic constant, $k_{\text {cat }}$. One interpretation of these results is that these residues are involved in a conformation change that accompanies the transition from the ground to catalytically active state. This conclusion may be important for the proposed effector function of this Arf GAP.

\section{EXPERIMENTAL}

\section{Plasmids}

Bacterial and mammalian expression vectors for ASAP1 have been described [1,24-26]. Single point mutations in the bacterial expression vector for $\mathrm{His}_{10}$-[325-724]ASAP1 (abbreviated as PZA in the text below) and the mammalian expression vector for full-length ASAP1 were introduced by the QuikChange ${ }^{\circledR}$ Site-directed Mutagenesis kit according to the manufacturer's protocols (Stratagene). The mutations were confirmed by sequencing. A construct for the expression of GST (glutathione Stransferase)-[275-724]ASAP1 was generated by inserting DNA encoding residues 275-724 of ASAP1 into the NotI and EcoRI sites of pGEX4T-1 (GE Healthcare). Plasmids for the mammalian expression of HA (haemagglutinin)-tagged Arf1 have been described in [27-29].

\section{Protein purification}

Human myrArf1 (myristoylated Arf1) protein was purified by a method modified from [30]. Pellets from 2-4 litres of bacteria cell culture were lysed in $20 \mathrm{mM}$ Tris ( $\mathrm{pH} 8.0$ ), $100 \mathrm{mM} \mathrm{NaCl}$, $1 \mathrm{mM} \mathrm{MgCl} 2,1 \mathrm{mM}$ DTT (dithiothreitol) and Complete ${ }^{\mathrm{TM}}$ protease inhibitor cocktail (Roche). The lysate was passed through a $5 \mathrm{ml}$ HiTrapQ HP (GE Healthcare). Material from the Q-column containing myrArf1 was fractionated on a $25 \mathrm{ml}$ phenylSepharose HP column in a $75 \mathrm{ml} \mathrm{NaCl}$ gradient from 3000 to $20 \mathrm{mM}$. Fractions containing myrArf1 were further purified by size exclusion using a Hiload 26/60 Superdex G75 column (GE Healthcare) in $20 \mathrm{mM}$ Tris (pH 8.0), $100 \mathrm{mM} \mathrm{NaCl}, 1 \mathrm{mM} \mathrm{MgCl}_{2}$, $1 \mathrm{mM}$ DTT and $10 \%(\mathrm{v} / \mathrm{v})$ glycerol. [L8K]Arf1 was purified as previously described [31]. His ${ }_{10}-$ [325-724]ASAP1 and point mutants of this protein were expressed and purified from bacteria as described in [26]. GST-[275-724]ASAP1 was purified with glutathione-Sepharose 4B beads following the manufacturer's protocol (GE Healthcare).

\section{GAP assays and kinetic analyses}

All reactions contained LUVs (large unilamellar vesicles) composed of $40 \%$ (mol fraction) phosphatidylcholine, $25 \%$ phosphatidylethanolamine, $15 \%$ phosphatidylserine, $7.5 \%$ phosphatidylinositol, $2.5 \%$ phosphatidylinositol 4,5-bisphosphate and $10 \%$ cholesterol prepared as previously described [10]. Lipids were purchased from Avanti Polar Lipids. The $C_{50}$ (the concentration of $\mathrm{His}_{10}$-[325-724]ASAP1 necessary for hydrolysis of $50 \%$ of the GTP bound to myrArf1 in a fixed time) was determined as described in [24,31]. For these experiments, only GTP bound to protein was analysed.

Single-turnover experiments (in which substrate was limiting but enzyme was saturating) and other rapid kinetic analyses were performed using a RQF-3 rapid chemical quench-flow instrument (KinTek, Austin, TX, U.S.A.). myrArf1 (3 $\mu \mathrm{M})$, incubated with $25 \mathrm{mM}$ Hepes (pH 7.5), $100 \mathrm{mM} \mathrm{NaCl}, 0.5 \mathrm{mM} \mathrm{MgCl}$, $1 \mathrm{mM}$ EDTA, $1 \mathrm{mM}$ ATP, $1 \mathrm{mM}$ DTT, $0.1 \mu \mathrm{M}\left[\alpha^{32} \mathrm{P}\right] \mathrm{GTP}$ and $500 \mu \mathrm{M}$ LUVs for $60 \mathrm{~min}$, was used as the substrate. His ${ }_{10}-[325-$ 724]ASAP1 (0.5-8 $\mu \mathrm{M}$, final concentration) with LUVs where indicated was rapidly mixed with Arf1-GTP at $30^{\circ} \mathrm{C}$. The reaction was quenched with $3.0 \mathrm{M}$ formic acid after $2 \mathrm{~ms}$ to $90 \mathrm{~s}$. GTP and GDP in the quenched reaction were separated by TLC on PEIcellulose [poly(ethyleneimine)-cellulose] as previously described $[26,32,33]$. In this analysis, unlike that used to determine $C_{50}$, the protein-bound GTP was not separated from the free GTP. The data plotted are the percentage of total GTP hydrolysed. The maximum hydrolysis achieved was equivalent to the fraction of GTP bound to Arf.

Kinetics under conditions satisfying the steady-state assumption were determined with a FluorMax 3 spectrophotometer (Jobin Yvon Horiba, Edison, NJ, U.S.A.) as described in [26,34] using the indicated recombinant ASAP1 protein as enzyme at concentrations ranging from $100 \mathrm{pM}$ to $100 \mathrm{nM}$ and $0.6-16 \mu \mathrm{M}$ myrArf1-GTP (considered the substrate) in a reaction containing $25 \mathrm{mM}$ Hepes (pH 7.5), $100 \mathrm{mM} \mathrm{NaCl}, 1.5 \mathrm{mM} \mathrm{MgCl} 2,1 \mathrm{mM}$ EDTA, $1 \mathrm{mM}$ DTT, $100 \mu \mathrm{M}$ GTP and $500 \mu \mathrm{M}$ LUVs. Fluorescence was recorded every $10 \mathrm{~s}$ to determine initial reaction rates.

\section{Determination of the association of ASAP1 with Arf1}

To measure formation of a GST-[275-724]ASAP1-Arf1GTP[S] complex, myrArf1 was loaded with GTP[S] by incubating the protein with $800 \mu \mathrm{M}$ GTP[S] in a buffer containing $25 \mathrm{mM}$ Hepes (pH 7.4), $100 \mathrm{mM} \mathrm{NaCl}, 0.5 \mathrm{mM} \mathrm{MgCl}, 1 \mathrm{mM}$ EDTA, $1 \mathrm{mM}$ DTT and $500 \mu \mathrm{M}$ LUVs for $60 \mathrm{~min}$ at $30^{\circ} \mathrm{C}$. $\mathrm{Mg}^{2+}$ was added to a final concentration of $2 \mathrm{mM}$ after the loading. myrArf1-GTP[S] $(1 \mu \mathrm{M})$ was incubated with $10 \mu \mathrm{M}$ GST-[275724]ASAP1 in a $100 \mu \mathrm{l}$ reaction containing $500 \mu \mathrm{M}$ LUVs and $10 \mu \mathrm{l}$ of glutathione-Sepharose $4 \mathrm{~B}$ beads for $60 \mathrm{~min}$ at $30^{\circ} \mathrm{C}$. The beads were separated from the bulk solution by centrifugation at $14000 \mathrm{~g}$ for $15 \mathrm{~s}$. The supernatant $(80 \mu \mathrm{l})$ was removed. SDS/ PAGE sample buffer was added to the beads and the remaining supernatant and the proteins were fractionated on an SDS/15\% polyacrylamide gel. Protein in the fraction containing the beads was quantified by Coomassie dye binding followed by densitometry.

\section{Cell culture and immunofluorescence}

NIH 3 T3 fibroblasts were maintained in DMEM (Dulbecco's modified Eagle's medium) containing $10 \%$ (v/v) fetal bovine serum with antibiotics. Cells were transfected with plasmids directing expression of the indicated proteins using Lipofectamine ${ }^{\mathrm{TM}}$ 2000 (Invitrogen). After $24 \mathrm{~h}$, cells were reseeded on fibronectincoated coverslips in Opti-MEM ${ }^{\circledR}$ medium (Invitrogen) for 5-7 h. The cells were then treated with $20-60 \mathrm{ng} / \mathrm{ml}$ PDGF (plateletderived growth factor) for 5-9 min and fixed in $4 \%$ formaldehyde. Immunostaining was performed as described in [25]. Arf1 was detected with a monoclonal antibody raised against the HA epitope (Roche). ASAP1 was detected with an antibody to the FLAG epitope (Sigma). Rhodamine-phalloidin was from Molecular Probes (Invitrogen). Images were captured by confocal microscopy (Carl Zeiss, model LSM 510). 


\section{Model construction}

Computational studies were performed on a Silicon Graphics Octane 2 workstation, equipped with dual $360 \mathrm{MHz}$ R12000 processors as described in [34]. The visualization of spatial surface was performed through Connolly's program (designated as Connolly surfaces). Figure 2 was generated using the Pymol program (http://www.pymol.org).

\section{Miscellaneous}

Numerical solutions to systems of ordinary, first order differential equations with variable coefficients were determined and data were fitted to these systems using Matlab (Mathworks, Natick, MA, U.S.A.) and KinTekSim (FreeWare from KinTek; http:// www.kintek-corp.com). Analytical solutions of systems of first order differential equations with constant coefficients were determined. Data were fitted to the final equations using GraphPad Prism (http://www.graphpad.com). Protein concentrations were determined by the Bio-Rad dye-binding assay (Bio-Rad, Hercules, CA, U.S.A.) and confirmed by absorbance at $280 \mathrm{~nm}$ [36].

\section{RESULTS}

We have examined the enzymatic activity of His ${ }_{10}$-[325-724]ASAP1, comprised of the PH (pleckstrin homology), Arf GAP and ANK domains of ASAP1, using myrArf1 as a substrate. The GAP reaction occurs on a lipid surface, which was presented as LUVs. By steady-state kinetic analysis the $K_{\mathrm{m}}$ and the $k_{\text {cat }}$ of ASAP1 for myrArf1 were determined to be $2.2 \pm$ $0.5 \mu \mathrm{M}$ and $57 \pm 5 \mathrm{~s}^{-1}$ respectively (Figure $1 \mathrm{~A}$ and Table 1). The $k_{\text {cat }}$ determined in single-turnover experiments was $56 \pm 7 \mathrm{~s}^{-1}$ (Figures $1 \mathrm{~B}$ and 1C). Similar to other Ras family proteins, tetrafluoroaluminate $\left(\mathrm{AlF}_{4}^{-}\right)$stabilized a complex of Arf1-GDP with ASAP1 (see Supplementary material and Supplementary Figure 1 at http://www.BiochemJ.org/bj/402/bj4020439add.htm). Based on these results, we conclude that GTP hydrolysis occurred within the binary complex of Arf1-GTP and ASAP1, similar to other Ras family proteins with their cognate GAPs.

The published crystal structures of Arf GAP1 [19] and PAP/ASAP2 [21] were used as a basis for a mutational analysis of the structural determinants for the GAP activity of ASAP1. In the crystal structure of [ $\Delta 17]$ Arf1-GDP-Arf GAP1, Arf1 forms salt bridges with Arg-60, Lys-68 and Glu-71 of Arf GAP1 [19]. We chose to change two analogous residues of ASAP1 (Gln-507 and Glu-518) to alanine. Mandiyan et al. [21], examining the crystal structure of the Arf GAP domain of PAP, identified a number of solvent-exposed residues, including Trp-274, Ile-285, Leu-306 and Asp-307 surrounding a highly conserved residue among Arf GAPs, Arg-292. The surface-exposed residues were proposed to contribute to binding Arf1-GTP. Arg-292 was presumed to directly stabilize the catalytic state by the same mechanism as the 'arginine fingers' of Ras GAPs and Rho GAPs [37]. Analogous residues to those thought to contribute to binding Arf in ASAP1, Trp-479, Ile-490, Leu-511 and Asp-512, and in inducing GTP hydrolysis, Arg-497, were changed (Figure 2). We also introduced mutations in two residues that were highly conserved among Arf GAPs, His-502 and Arg-505, and in one residue in the PH domain, Arg-360 [34,35]. The mutants generated are summarized in Table 1. Retention of structure was determined by CD spectroscopy (see Supplementary Figure 2 at http://www.BiochemJ.org/ bj/402/bj4020439add.htm). No differences among the proteins were found.

The efficiency of the mutant ASAP1 proteins as GAPs was determined by finding the concentration $\left(C_{50}\right)$ at which $50 \%$ of the
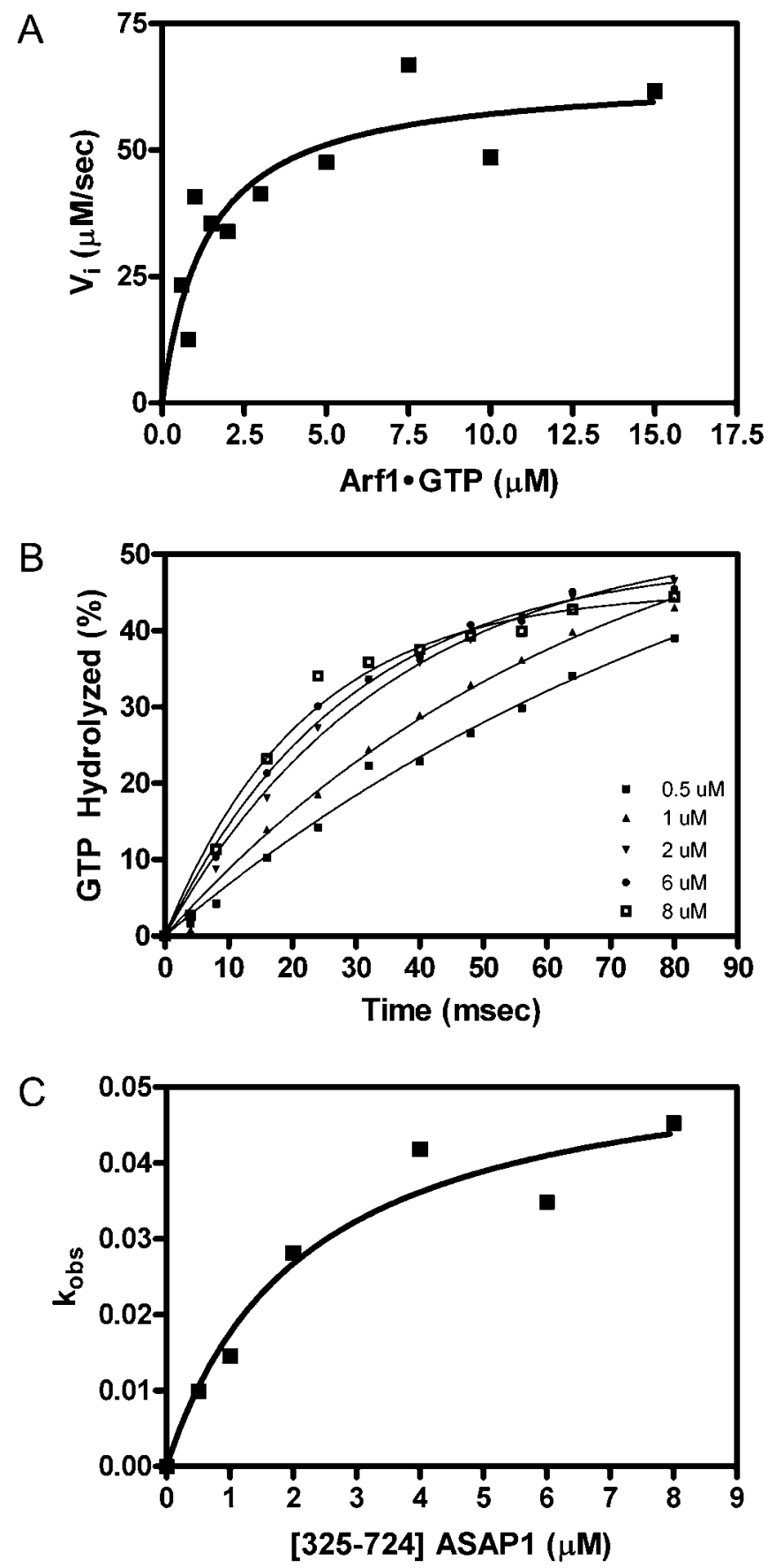

Figure 1 Kinetic analysis of ASAP1-catalysed GTP hydrolysis on Arf

(A) Steady-state analysis of the reaction catalysed by His ${ }_{10}$-[325-724]ASAP1. In these experiments, Arf1-GTP was monitored by fluorescence [26]. Reactions contained 400 pM $\mathrm{His}_{10}$-[325-724]ASAP1 and 0.6-16 $\mu \mathrm{M}$ myrArf1-GTP. Reactions were initiated by the addition of ASAP1. Initial slopes of the change in fluorescence were determined. Reaction rates were calculated from the initial slope data. The plot of Arf1 concentration versus reaction rate was fitted to the Michaelis-Menten equation and used to estimate $V_{\max }$ and $K_{\mathrm{m}}$. (B) Single-turnover kinetic analysis of the reaction catalysed by $\mathrm{His}_{10}$-[325-724]ASAP1. myrArf1-GTP was rapidly mixed with the indicated concentrations of [325-724]ASAP1. Reactions were quenched by rapid mixing with formic acid at the indicated times. The data were fitted to firstorder rate equations. (C) Replot of single-turnover kinetic analysis to determine $k_{\text {cat }}$. The rates estimated from fitting the data in (B) were plotted against the concentration of ASAP1 added to the reaction. The maximum rate, $k_{\text {cat }}$, was estimated by fitting these data to the equation:

$k_{\mathrm{obs}}=\mathrm{ASAP} 1 \cdot k_{\mathrm{cat}} /\left(\mathrm{ASAP} 1+K_{\mathrm{m}}\right)$

Representative experiments of three are shown. 


\section{Table 1 Kinetic characterization of [325-724]ASAP1 and mutants}

$C_{50}$ (concentration of enzyme required to complete $50 \%$ of the reaction in $3 \mathrm{~min}$ ) values were determined as described in [23]. $K_{\mathrm{m}}$ and $k_{\text {cat }}$ values were derived from rate experiments performed under conditions satisfying the steady-state assumptions (ASAP1 $\ll K_{\mathrm{m}}$ and Arf1-GTP). The $k_{\text {cat }}$ was also determined in single-turnover experiments. All reported results are the means \pm S.D. for three experiments.

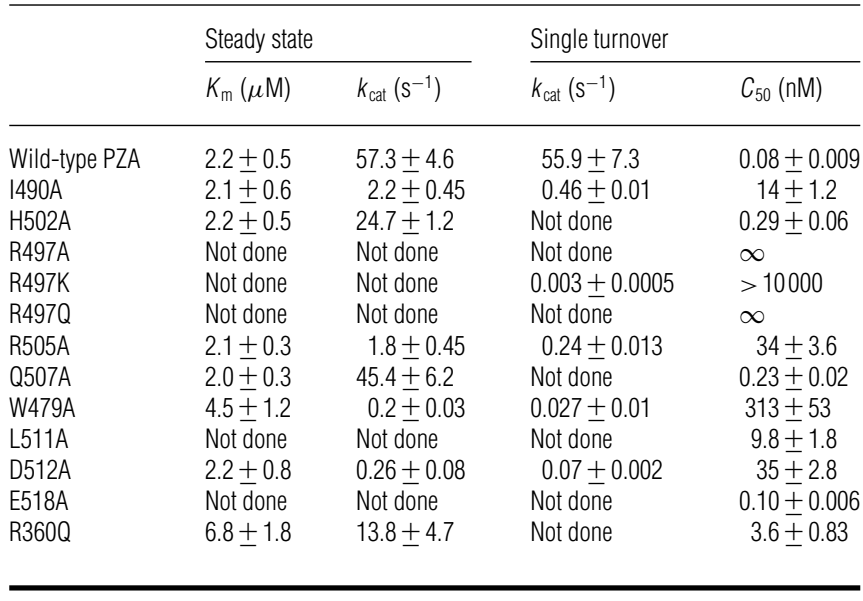

GTP on Arf was hydrolysed (Table 1, see Figure 3A for example of data used to determine a $C_{50}$ ). For these experiments, we used LUVs as a surface for the reaction (in some previous work, mixed micelles were used, e.g. [23]). Three mutations, H502A, Q507A and E518A, had little or no effect on activity compared with wild-type protein. Mutation of Arg-360 had a 40-fold effect on the $C_{50}$, Ile-490 to alanine and Leu-511 to alanine an approx. 100-fold effect, Arg-505 to alanine and Asp-512 to alanine a 500-fold effect and Trp-479 to alanine an approx. 4000-fold effect. Proteins with Arg-497 mutated had too little activity to determine a $C_{50}$ [23]. [R497K]ASAP1 induced limited hydrolysis in the 3 min assay containing saturating amounts of GAP (Figure 3B). [R497Q]ASAP1 and [R497A]ASAP1 had no detectable activity at concentrations as high as $40 \mu \mathrm{M}$ in a 3 min assay.

The difference in enzymatic activity could result from either changes in substrate-enzyme association (i.e. changes in $K_{\mathrm{m}}$ ) or in the catalytic constant $\left(k_{\text {cat }}\right)$. For those mutants with detectable GAP activity, we examined saturation kinetics as a first step in distinguishing between these two possibilities (Table 1, also see Figure 4 for an example of a saturation curve using [D512A,325724]ASAP1). As expected based on the $C_{50}$ analysis, mutation of Gln-507 had no detectable effect on either $K_{\mathrm{m}}$ or $k_{\text {cat }}$ and mutation of His-502 had a minimal effect ( $\sim 2$-fold) on $k_{\text {cat }}$ with no effect on $K_{\mathrm{m}}$. Mutation of Trp-479 and Arg-360 increased the $K_{\mathrm{m}}$ by 2-4-fold. However, different than predicted, none of the other mutations affected the $K_{\mathrm{m}}$. Also different than predicted, mutation of Ile-490 and Arg-505 reduced the $k_{\text {cat }}$ to less than $3 \%$ that of wild-type ASAP1 and mutation of Trp-479 and Asp-512 reduced $k_{\text {cat }}$ to less than $0.5 \%$ of the $k_{\text {cat }}$ of the wild-type protein.

For those proteins with very low GAP activity, we determined if they could inhibit the reaction, presumably by sequestering Arf. [R497A]ASAP1 and [R497Q]ASAP1 were titrated into a GAP reaction containing wild-type GAP and Arf1-GTP. Each of the proteins inhibited activity (Figure 5A). The $K_{\mathrm{i}}$ values, which would be equivalent to affinity assuming inhibition is the result of binding Arf1-GTP, were within an order of magnitude of the $K_{\mathrm{m}}$ for the wild-type PZA-Arf interaction $(13 \pm 1.6 \mu \mathrm{M}$ for [R497Q] and $11 \pm 1.5 \mu \mathrm{M}$ for [R497A]). Based on this result, we conclude that the mutations primarily affect the $k_{\text {cat }}$. As an independent test for binding of Arf1-GTP to [R497K]ASAP1, GST, GST-[275724]ASAP1 and GST-[R497K, 275-724]ASAP1 were incubated
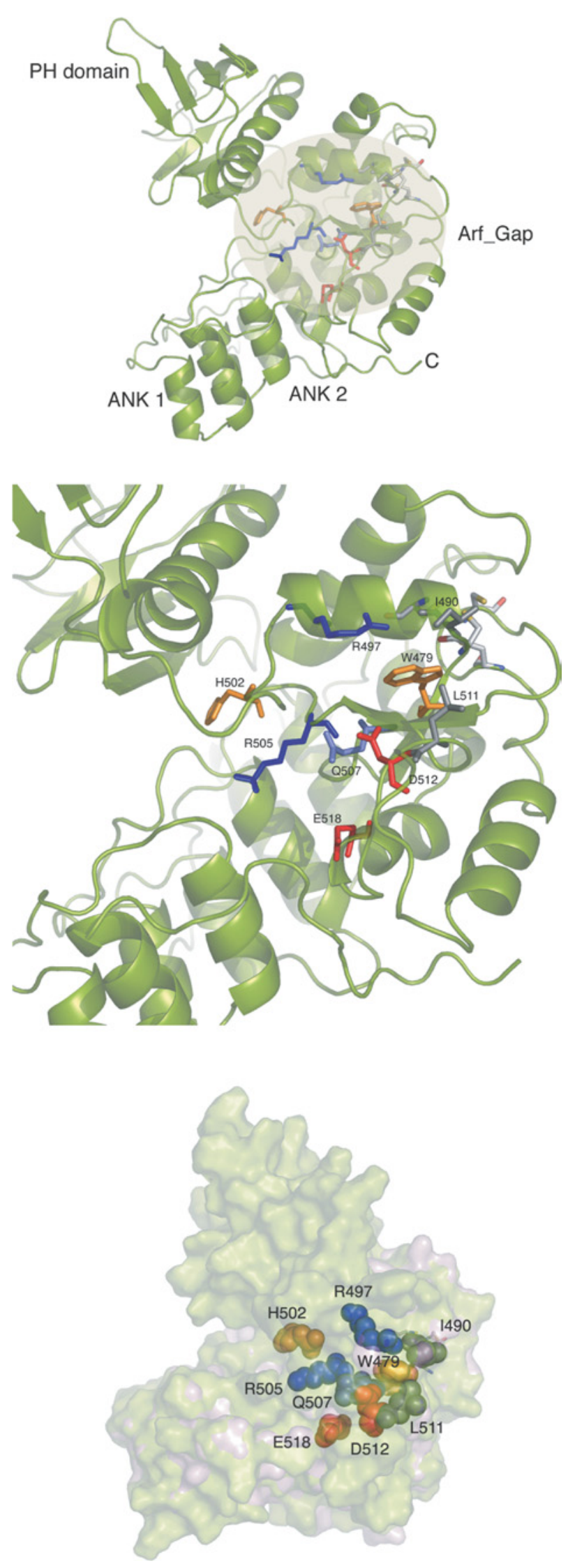

Figure 2 Mutants analysed in the present studies

Homology structure of Arf GAP and ANK domains of ASAP1 with mutated residues indicated. 


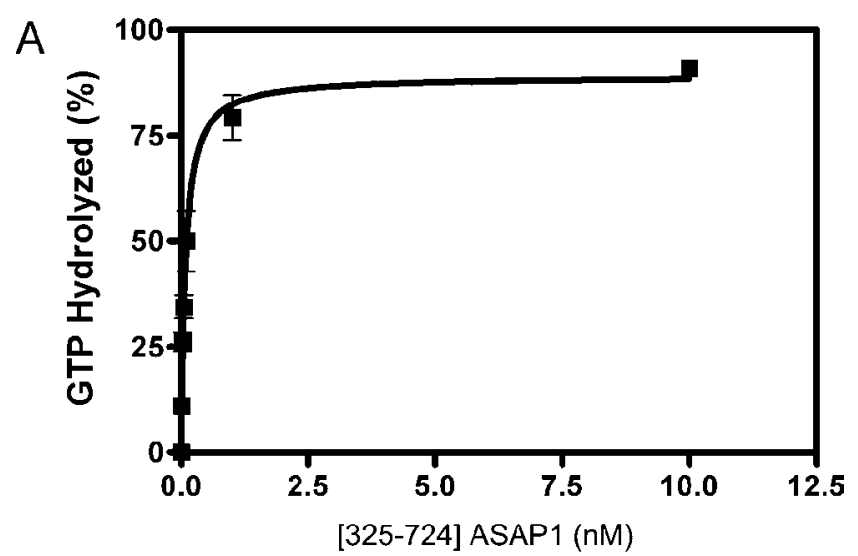

$\mathrm{B}$

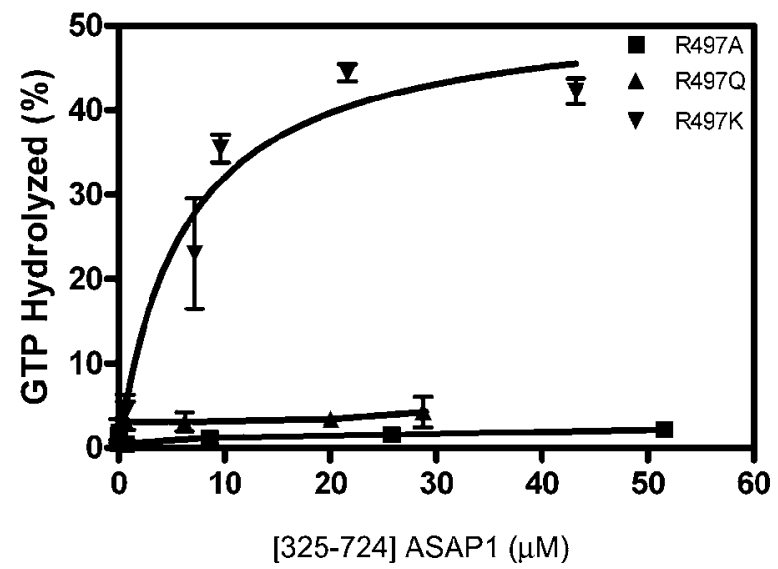

Figure 3 Comparison of enzymatic power of mutants of $\mathrm{His}_{10}-[325-$ 724]ASAP1

(A) Wild-type His ${ }_{10}$-[325-724]ASAP1 was titrated into a reaction containing myrArf1-GTP. Reactions were stopped after $3 \mathrm{~min}$ by dilution with $20 \mathrm{mM}$ Tris (pH 8.0), $10 \mathrm{mM} \mathrm{MgCl}$, $100 \mathrm{mM} \mathrm{NaCl}$ and $1 \mathrm{mM} \mathrm{DTT}$ at $4^{\circ} \mathrm{C}$. Protein-bound nucleotide was trapped on nitrocellulose, eluted with formic acid and separated by TLC. (B) Effect of changes in Arg-497 of ASAP1. The experiment was performed as described in $(\mathbf{A})$. Note the difference from $(\mathbf{A})$ in both scales with up to $60 \mu \mathrm{M}$ protein and less than $50 \%$ of the GTP hydrolysed. Results are from three experiments.

with Arf1-GTP[S]. GST or the fusion proteins were precipitated with glutathione beads and the amount of Arf1 in the precipitate was measured (Figure 5B). Arf1 is precipitated with both wild-type and [R497K]ASAP1 but not with GST.

A change in the $k_{\text {cat }}$ calculated from steady-state data could result from either an actual change in the rate of decomposition of the enzyme-substrate complex or a change in the amount of properly folded GAP. To distinguish between these two possibilities we examined a single round of GTP hydrolysis using saturating levels of enzyme (Table 1 and Figure 6 for an example of data for one mutant, [D512A, 325-724]ASAP1). By this analysis, [R497K]ASAP1 had 1:13000 the activity of wild-type ASAP1. The results for the other mutants were consistent with steadystate kinetics; the defect in GTP hydrolysis was primarily a consequence of a change in $k_{\text {cat }}$.

Our results indicate that ASAP1 may undergo a rate-limiting conformational change on binding the substrate Arf1-GTP. The conformational change is represented as the ES to $\mathrm{E}^{*} \mathrm{~S}$ reaction in Scheme I presented in Figure 7(A). In previous reports, ASAP1 was proposed to undergo a conformational change on binding membranes [34], represented by $\mathrm{E}$ to $\mathrm{E}^{*}$ transition in Scheme II presented in Figure 7(A). To test if this putative conformational

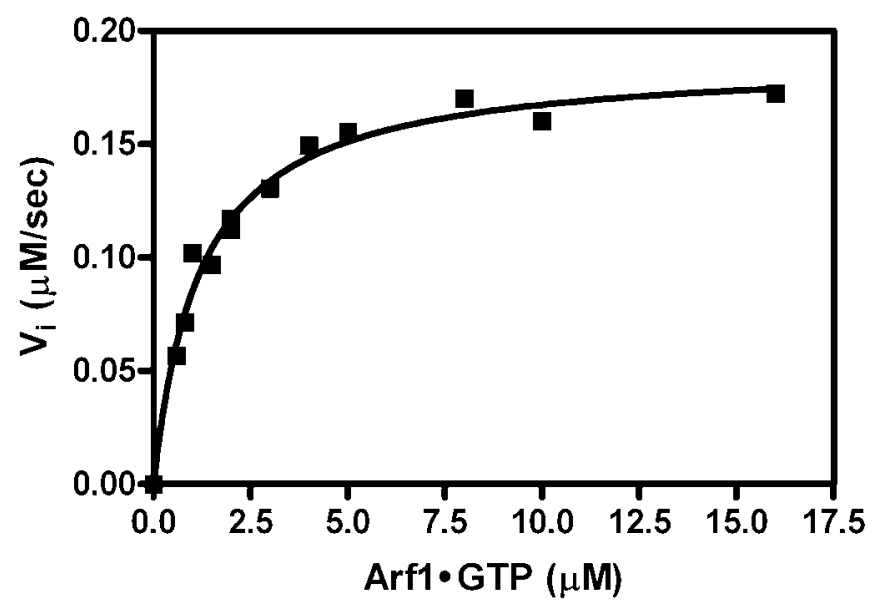

Figure 4 Steady-state kinetic analysis of $\mathrm{His}_{10}$-[D512A,325-724]ASAP1

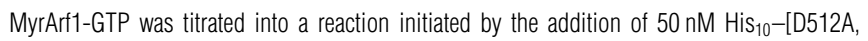
325-724]ASAP1. myrArf1-GTP was monitored by fluorescence. Initial rates were estimated from the time course data. A plot of initial velocity versus myrArf1-GTP concentration is shown. The results were fitted to the Michaelis-Menten equation to obtain estimates of $K_{\mathrm{m}}$ and $V_{\text {max }}$. The $k_{\text {cat }}$ was calculated from the $V_{\max }$ and enzyme concentration. The experiment shown is representative of three.

change was rate-limiting, single-turnover kinetics were performed with [L8K]Arf1, a mutant that can bind GTP in the absence of lipids or detergent. In this case, reaction rates could be determined with either ASAP1 or Arf1 premixed with lipids. No difference in rates was observed and the rates were similar to that observed with myrArf1 (Figure 7B). In addition, single-turnover reaction rates were compared using myrArf1 premixed with lipids (to stabilize Arf1-GTP) and ASAP1 either in solution or premixed with lipids (Figure 7C). Again, the reaction rates were indistinguishable, indicating that association/dissociation kinetics from lipids, and accompanying conformational changes, were not rate-limiting.

In the case of [W479A]ASAP1 and [D512A]ASAP1, the single-round turnover rates were slower than the $k_{\text {cat }}$ measured under conditions in which the steady-state assumption was satisfied. We considered two explanations for this result. One is that the conformational change on binding membranes is rate-limiting for these mutants, represented by Scheme II in Figure 7(A). The other possibility was that the GAP remains in an active conformation for sufficient time after product dissociation to allow the substrate Arf1-GTP to bind GAP in the active, rather than the ground state, depicted in Scheme III. Simulations indicated that either could explain the discrepancy (results not shown). We used a premixing experiment with [L8K]Arf1, as described for the wild-type protein, to determine whether, as in Scheme II, a conformational change on lipid binding was rate-limiting. As for the wild-type protein, we did not observe a difference in rates between the two conditions (Figure 7D). Regardless of the explanation for the discrepancy between the $k_{\text {cat }}$ determined under the two conditions, the primary effect of the mutations is to slow substrate to product conversion by influencing one or both steps in the reaction sequence $\mathrm{ES} \rightarrow \mathrm{E}^{*} \mathrm{~S} \rightarrow \mathrm{E}^{*} \mathrm{P}$.

We also examined the in vivo activity of several ASAP1 mutants using NIH 3 T3 fibroblasts as a model. PDGF treatment in these cells induces the formation of dorsal ruffles, detected by staining for polymerized actin (see Figure 8). Overexpression of wildtype ASAP1 reduced the formation of dorsal ruffles as previously reported [25], but associated with ruffles that formed (Figures 8A and 8B). Like wild-type ASAP1, [R497K]ASAP1, [R505A]ASAP1 and [D512A]ASAP1, which lack GAP activity, 

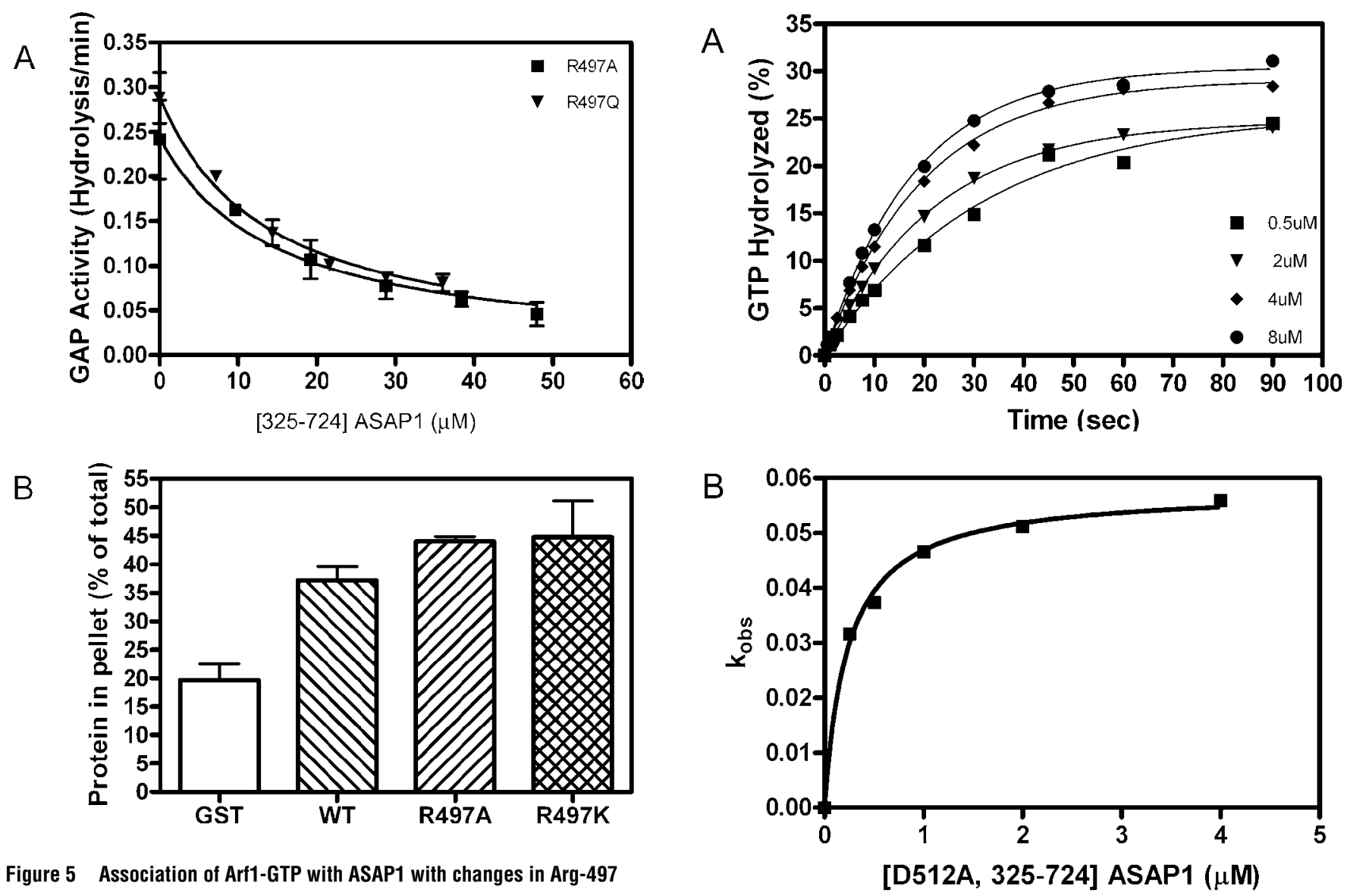

Figure 5 Association of Arf1-GTP with ASAP1 with changes in Arg-497

\begin{abstract}
(A) Inhibition of GAP activity by wild-type ASAP1. His $10-[R 497 A, 325-724] A S A P 1$ or $\mathrm{His}_{10}$-[R497Q,325-724]ASAP1 were titrated into a reaction containing $0.5 \mathrm{nM}$ His ${ }_{10}$-[325-724]ASAP1 and approx. $10 \mathrm{nM}$ Arf1-GTP. Reaction rates are plotted against concentration of inactive ASAP1 mutant. Assuming the ASAP1 mutants inhibited by sequestering the substrate, the affinity for substrate is the $K_{\mathrm{i}}$ calculated from fitting the data to the equation $k_{\text {obs }}=k_{\max } /\left(1+\right.$ mutant $\left./ K_{\mathrm{i}}\right)$. (B) Arf1-GTP[S] binding to GST-[275-724]ASAP1. myrArf1GTP[S] $(\mu \mathrm{M})$ was incubated with $10 \mu \mathrm{M}$ GST-[275-724]ASAP1 or the indicated mutants. Protein association was determined as described in the Experimental section. The results presented are the average for three experiments.
\end{abstract}

associated with dorsal ruffles. In contrast with cells expressing wild-type ASAP1, cells expressing [R497K]ASAP1 were more likely to have circular ruffles after a 9 min treatment with PDGF than were control cells expressing GFP (green fluorescent protein). [R505A]ASAP1 and [D512A]ASAP1 did not affect the formation of dorsal ruffles. Consistent with reduced GAP activity, the three mutants co-localized with Arf1 in the dorsal ruffles (Figure 8C).

\section{DISCUSSION}

We have examined the interaction of the Arf GAP-ASAP1 with Arf1 in experiments designed to test predictions based on two crystallographic studies. Our results agree with two conclusions based on crystallization of PAP, a close homologue of ASAP1. First, ASAP1 acts in binary complex with Arf1-GTP to catalyse hydrolysis of GTP. Secondly, an arginine residue from ASAP1 contributes to formation of the transition state towards GTP hydrolysis. However, some results were not consistent with conclusions of either of the previous reports. Several residues predicted either to have no effect on catalysis or to affect Arf binding to the GAP instead affected the catalytic constant. These residues are confined to one surface of the GAP domain. One
Figure 6 Analysis of single-turnover kinetics for $\mathrm{His}_{10}$-[D512A,325724]ASAP1

Reactants were rapidly mixed and the reaction quenched as described in the legend of Figure 1(B) and the Experimental section. This Figure shows a representative experiment of three performed using [D512A,325-724]ASAP1. (A) Time course for GTP hydrolysis with various ASAP1 concentrations. (B) Plot of $k_{\text {obs }}$ determined from $(\mathbf{A})$ against ASAP1 concentration.

interpretation of our results is that ASAP1 undergoes a ratelimiting conformational change involving a significant surface of the protein, which may be important for the putative effector function of ASAP1.

\section{The GAP stabilizes the transition state towards GTP hydrolysis}

In contrast with reports for Arf GAP1 [19], ASAP1 does not appear to require an additional protein to promote GTP hydrolysis. In a system in which the only two proteins present are ASAP1 and Arf1, the $k_{\text {cat }}$ was $\sim 60 \mathrm{~s}^{-1}$. For comparison, the $k_{\text {cat }}$ for Ras GAP and p50 Rho GAP are $\sim 10 \mathrm{~s}^{-1}$ and $1-5 \mathrm{~s}^{-1}$ [38-42]. Furthermore, like Ras GAP and Rho GAP [40,43-45], a complex of the GAP with the GDP-bound Arf was stabilized with $\mathrm{AlF}_{4}{ }^{-}$, consistent with the formation of the transition state towards hydrolysis while in binary complex (see Supplementary material at http://www.BiochemJ.org/bj/402/bj4020439add.htm). The measured rate is at least as fast as the rate of the processes being controlled by Arf1; therefore acceleration of this rate is not likely to be necessary for function.

\section{Arg-497 of ASAP1 may function as an 'arginine finger'}

Our results support the idea that Arg-497 is important for forming a transition state complex. A conservative change to a lysine 


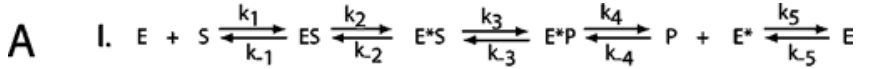

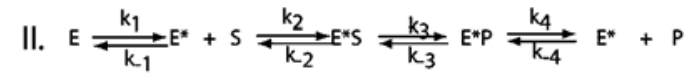

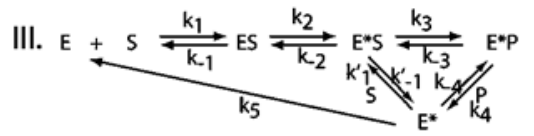

B

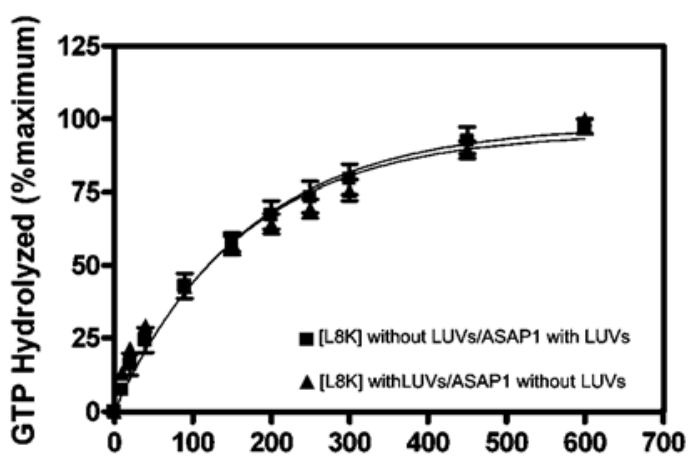

C

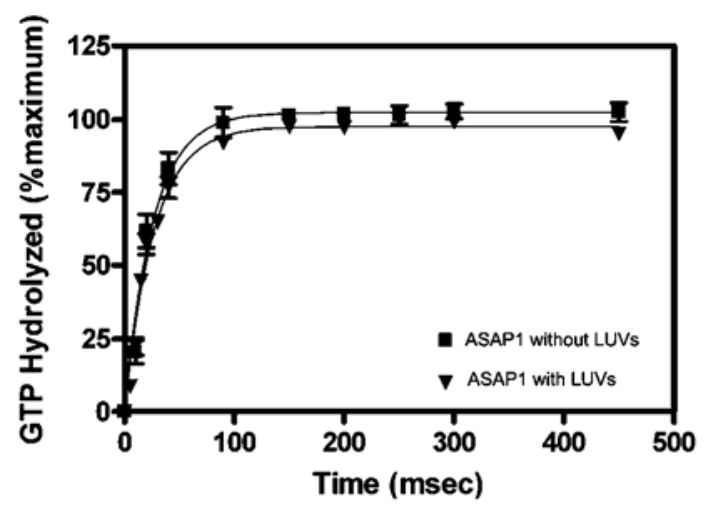

D

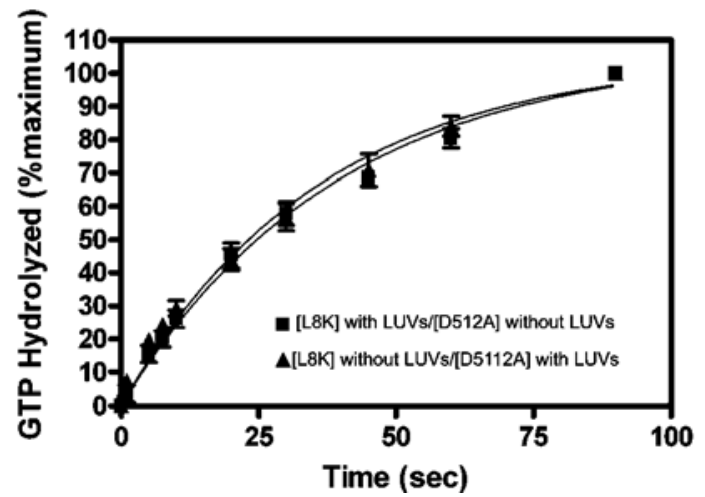

Figure 7 Effect of premixing ASAP1 with lipid on single-turnover reaction rates

(A) Kinetic schemes. E represents the Arf GAP-ASAP1, S is Arf1-GTP and P is Arf1-GDP. Asterisk indicates a distinct conformational state. (B) [L8K]Arf1-GTP as substrate. Either His $_{10}$-[325-724]ASAP1 or [L8K]Arf1-GTP were premixed with vesicles, as indicated, prior to rapid mixing and quenching of the reaction. (C) myrArf1-GTP as substrate. myrArf1-GTP, prepared with LUVs (myrarf1-GTP is not stable without a hydrophobic surface), was rapidly mixed with $\mathrm{His}_{10}$-[325-724]ASAP1 that had been premixed with LUVs. Reactions were quenched after the indicated incubation times. (D) Effect of Asp-512 on the lipid association step in the GAP reaction. This experiment was performed identically with the experiment described in $(\mathbf{A})$ but used $\mathrm{His}_{10}$-[D512A,325-724]ASAP1 as the GAP. The results shown are from three independent experiments. residue results in a protein with 1:100000 the activity of the wildtype protein, due to a $k_{\text {cat }} 1: 13000$ that of the wild-type protein and a $K_{\mathrm{d}}$ approx. 7-fold greater than that of wild-type ASAP1. However, we cannot assert that Arg-497 has an analogous function as Arg-789 in Ras GAP or Arg-282 in Rho GAP p50. These arginine residues have been examined in crystallographic models of transition state complexes [37]. They insert into the active site and neutralize the negative charge that concentrates on the $\gamma$ phosphate during hydrolysis. Testing the hypothesis that Arg-497 of ASAP1 has an analogous function will require similar structural data.

Our results are consistent with the idea that ASAP1 undergoes a significant conformational change coincident with switching from the ground state of Arf1-GTP binding to the transition state towards GTP hydrolysis

The number of mutations that affected the $k_{\text {cat }}$ of ASAP1 was unexpected. Most mutations that we examined were predicted to affect the $K_{\mathrm{m}}$ because the residues changed, based on the modelling, were on the surface of the GAP domain around the putative catalytic arginine residue [21]. The possibility that all the residues contributed to chemical catalysis is unlikely. They encompass approx. $12000 \AA^{2}$ and could not all insert into the active site. The lack of effect on $K_{\mathrm{m}}$, in addition to the CD spectrometry results, indicated that the mutations had not affected the conformation of the ground state of the ASAP1. One explanation for the results was that mutation of Arg-497 affected chemical catalysis, whereas other mutations affected a process such as a conformational change necessary for achieving the transition state towards GTP hydrolysis. Some of the mutated residues affecting $k_{\text {cat }}$, such as Arg-505, may interact with the PH domain. In a previous study, we have found that a conformation change transmitted through the PH domain contributed to GTP hydrolysis [34]. Furthermore, protection studies together with computer modelling support the idea that there is an interface between the PH and GAP domains of ASAP1 that includes Arg-505 [34]. Other residues whose change affected the $k_{\text {cat }}$, however, were not in the interface predicted from the modelling work. Additional structural studies are necessary if the roles of these residues in catalysis are to be determined.

\section{A conformational change going from the ground to transition state is consistent with the mechanical function of ASAP1 and proposed physiological role in membrane traffic}

ASAP1 has been found to induce curvature of membranes dependent on acid phospholipids and Arf $1-\mathrm{p}[\mathrm{NH}] \mathrm{ppG}$ (guanosine $5^{\prime}$-[ $\beta \gamma$-imido]triphosphate) [10]. Bending membranes is an early step in generating a transport vesicle. We have speculated that a conformational change coincident with going from the ground to the catalytically active state is also coincident with a transition from a flat to a bent membrane, thereby linking the two events. The difference in $k_{\text {cat }}$ determined by steady-state and single-turnover kinetic studies (as observed for some mutants, see Table 1) could indicate the conformational change is hysteretic. Differences in conformational state may account for the effects of the mutants on dorsal ruffle formation. In the scheme $\mathrm{ES} \rightarrow \mathrm{E}^{*} \mathrm{~S} \rightarrow \mathrm{E}^{*} \mathrm{P}$, we have speculated that changes in Arg-497 affect $E^{*} S \rightarrow E^{*} P$, whereas change in Arg-505 and Asp-512 affects ES $\rightarrow E^{*} S$. If $\mathrm{E}^{*} \mathrm{~S}$ is linked to ruffle formation and ES is not, then expression of [R497K]ASAP1 expression could result in a greater number of cells containing dorsal ruffles. [R505A]ASAP1 and [D512A]ASAP1, achieving the $\mathrm{E}^{*} \mathrm{~S}$ state slowly, may have no effect in the background of endogenous ASAP1. The nature of the conformational change and its relationship to other domains 
A
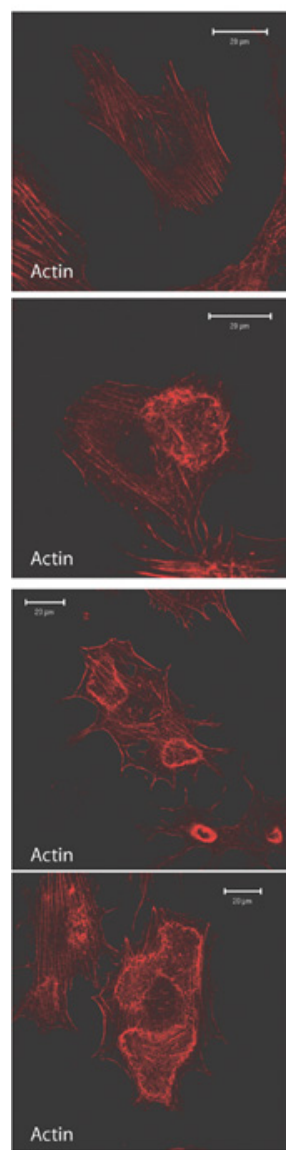

Actin
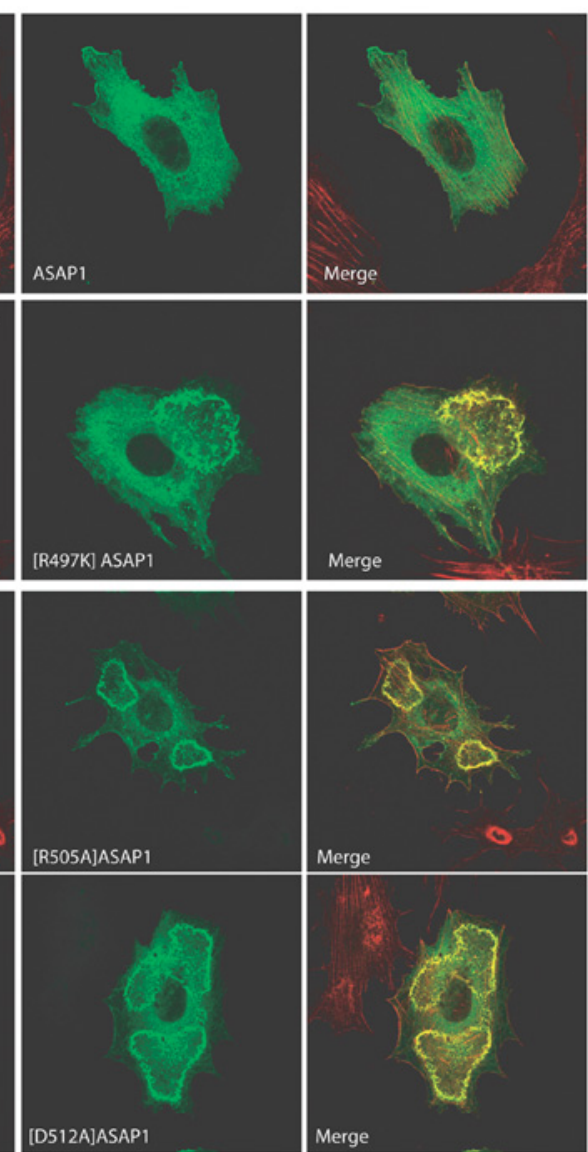

C
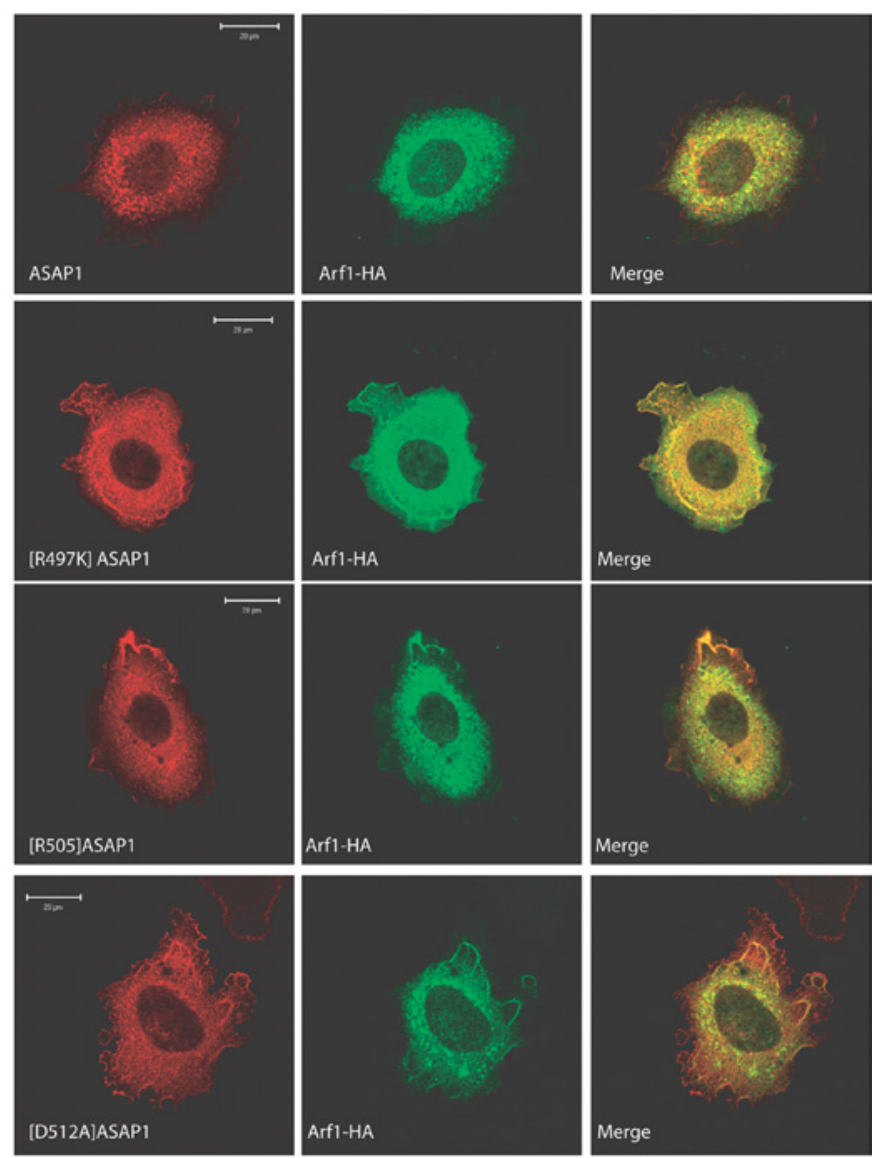

B

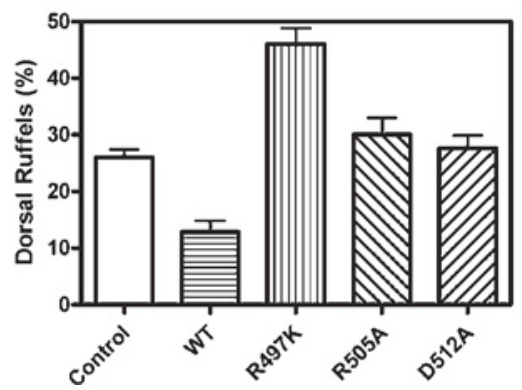

\section{Figure 8 Mutants of ASAP1 in cells}

(A) Distribution of ASAP1. The indicated mutants of FLAG-tagged ASAP1 were expressed in NIH 3T3 fibroblasts. GFP was expressed in control cells. After $24 \mathrm{~h}$, the cells were reseeded on fibronectin-coated coverslips, incubated for $5 \mathrm{~h}$ in serum-free medium and treated for 5 min with $60 \mathrm{ng} / \mathrm{ml}$ PDGF. Cells were fixed. Actin was visualized with rhodamine-phalloidin and ASAP1 visualized by staining for the FLAG epitope. (B) Effect on dorsal ruffle formation. Results are the percentage of cells expressing the indicated proteins with dorsal ruffles after a 9 min treatment with $20 \mathrm{ng} / \mathrm{ml} \mathrm{PDGF}$. Results are from four experiments, with 50 cells scored per condition in each experiment. (C) Co-localization with Arf1. ASAP1 was c0-expressed with Arf1-HA in NIH 3T3 fibroblasts. Cells were treated as described in (A) but Arf1 and ASAP1 were visualized by immunostaining.

in the protein as well as to the cellular function of ASAP1 are being examined in ongoing studies.

We thank Dr Yaiwen Bai and Dr Zheng Zhou (Center for Cancer Research, National Cancer Institute) for help with CD spectropolarimetry, Susan Garfield and Stephen Wincovitch of the National Cancer Institute confocal core for help with microscopy. This work was supported by the Intramural Research Program of the National Cancer Institute and the National Institute of Arthritis and Musculoskeletal and Skin Diseases.

\section{REFERENCES}

1 Brown, M. T., Andrade, J., Radhakrishna, H., Donaldson, J. G., Cooper, J. A. and Randazzo, P. A. (1998) ASAP1, a phospholipid-dependent Arf GTPase-activating protein that associates with and is phosphorylated by Src. Mol. Cell. Biol. 18, 7038-7051

2 Cukierman, E., Huber, I., Rotman, M. and Cassel, D. (1995) The ARF1 GTPase-activating protein - zinc-finger motif and Golgi complex localization. Science 270, 1999-2002

3 Randazzo, P. A. and Hirsch, D. S. (2004) Arf GAPs: multifunctional proteins that regulate membrane traffic and actin remodelling. Cell. Signalling 16, 401-413 
4 Schmalzigang, R. and Premont, R. T. (2003) GIT proteins: Arf GAPs and signaling scaffolds. In Arf Family GTPases (Kahn, R. A., ed.), pp. 159-184, Kluwer, Dordrecht

5 Turner, C. E., West, K. A. and Brown, M. C. (2001) Paxillin-ARF GAP signaling and the cytoskeleton. Curr. Opin. Cell Biol. 13, 593-599

6 Turner, C. E., Brown, M. C., Perrotta, J. A., Riedy, M. C., Nikolopoulos, S. N., McDonald, A. R., Bagrodia, S., Thomas, S. and Leventhal, P. S. (1999) Paxillin LD4 motif binds PAK and PIX through a novel 95-kD ankyrin repeat, ARF-GAP protein: a role in cytoskeletal remodeling. J. Cell Biol. 145, 851-863

7 Zhao, Z. S., Manser, E., Loo, T. H. and Lim, L. (2000) Coupling of PAK-interacting exchange factor PIX to GIT1 promotes focal complex disassembly. Mol. Cell. Biol. 20, 6354-6363

8 Zhang, C. J., Cavenagh, M. M. and Kahn, R. A. (1998) A family of Arf effectors defined as suppressors of the loss of Arf function in the yeast Saccharomyces cerevisiae. J. Biol. Chem. 273, 19792-19796

9 Yang, J. S., Lee, S. Y., Gao, M. G., Bourgoin, S., Randazzo, P. A., Premont, R. T. and Hsu, V. W. (2002) ARFGAP1 promotes the formation of COPI vesicles, suggesting function as a component of the coat. J. Cell Biol. 159, 69-78

10 Nie, Z., Hirsch, D. S., Luo, R., Jian, X., Stauffer, S., Cremesti, A., Andrade, J., Lebowitz, J., Marino, M., Ahvazi, B. et al. (2006) A BAR domain in the N terminus of the Arf GAP ASAP1 affects membrane structure and trafficking of epidermal growth factor receptor. Curr. Biol. 16, 130-139

11 Ehlers, J. P., Worley, L., Onken, M. D. and Harbour, J. W. (2005) DDEF1 is located in an amplified region of chromosome $8 \mathrm{q}$ and is overexpressed in uveal melanoma. Clin. Cancer Res. 11, 3609-3613

12 Donaldson, J. G. and Jackson, C. L. (2000) Regulators and effectors of the ARF GTPases. Curr. Opin. Cell Biol. 12, 475-482

13 Moss, J. and Vaughan, M. (1998) Molecules in the ARF orbit. J. Biol. Chem. 273, 21431-21434

14 Randazzo, P. A., Nie, Z., Miura, K. and Hsu, V. (2000) Molecular aspects of the cellular activities of ADP-ribosylation factors. Science STKE 59, RE1

15 Bonifacino, J. S. and Glick, B. S. (2004) The mechanisms of vesicle budding and fusion. Cell 116, 153-166

16 Rothman, J. E. (2002) The machinery and principles of vesicle transport in the cell. Nat. Med. 8, 1059-1062

17 Nie, Z., Boehm, M., Boja, E., Vass, W., Bonifacino, J., Fales, H. and Randazzo, P. A. (2003) Specific regulation of the adaptor protein complex AP-3 by the Arf GAP AGAP1. Dev. Cell 5, 513-521

18 Nie, Z. Z., Fei, J., Premont, R. T. and Randazzo, P. A. (2005) The Arf GAPs AGAP1 and AGAP2 distinguish between the adaptor protein complexes AP-1 and AP-3. J. Cell Sci. 118, 3555-3566

19 Goldberg, J. (1999) Structural and functional analysis of the ARF1-ARFGAP complex reveals a role for coatomer in GTP hydrolysis. Cell 96, 893-902

20 Goldberg, J. (2000) Decoding of sorting signals by coatomer through a GTPase switch in the COPI coat complex. Cell 100, 671-679

21 Mandiyan, V., Andreev, J., Schlessinger, J. and Hubbard, S. R. (1999) Crystal structure of the ARF-GAP domain and ankyrin repeats of PYK2-associated protein $\beta$. EMBO J. 18 6890-6898

22 Szafer, E., Pick, E., Rotman, M., Zuck, S., Huber, I. and Cassel, D. (2000) Role of coatomer and phospholipids in GTPase-activating protein-dependent hydrolysis of GTP by ADP-ribosylation factor-1. J. Biol. Chem. 275, 23615-23619

23 Luo, R. B., Jacques, K., Ahvazi, B., Stauffer, S., Premont, R. T. and Randazzo, P. A. (2005) Mutational analysis of the Arf1 center dot GTP/Arf GAP interface reveals an Arf1 mutant that selectively affects the Arf GAP ASAP1. Curr. Biol. 15, 2164-2169

24 Jacques, K. M., Nie, Z. Z., Stauffer, S., Hirsch, D. S., Chen, L. X., Stanley, K. T. and Randazzo, P. A. (2002) Arf1 dissociates from the clathrin adaptor GGA prior to being inactivated by arf GTPase-activating proteins. J. Biol. Chem. 277, 47235-47241

25 Randazzo, P. A., Andrade, J., Miura, K., Brown, M. T., Long, Y. Q., Stauffer, S., Roller, P. and Cooper, J. A. (2000) The Arf GTPase-activating protein ASAP1 regulates the actin cytoskeleton. Proc. Natl. Acad. Sci. U.S.A. 97, 4011-4016

Received 8 August 2006/9 November 2006; accepted 20 November 2006

Published as BJ Immediate Publication 20 November 2006, doi:10.1042/BJ20061217
26 Che, M. M., Nie, Z. Z. and Randazzo, P. A. (2005) Assays and properties of the Arf GAPs AGAP1, ASAP1, and Arf GAP1. Methods Enzymol. 404, 147-163

27 Teal, S. B., Hsu, V. W., Peters, P. J., Klausner, R. D. and Donaldson, J. G. (1994) An activating mutation in Arf1 stabilizes coatomer binding to Golgi membranes. J. Biol. Chem. 269, 3135-3138

28 Radhakrishna, H. and Donaldson, J. G. (1997) ADP-ribosylation factor 6 regulates a novel plasma membrane recycling pathway. J. Cell Biol. 139, 49-61

29 Radhakrishna, H., Klausner, R. D. and Donaldson, J. G. (1996) Aluminum fluoride stimulates surface protrusions in cells overexpressing the ARF6 GTPase. J. Cell Biol. 134, 935-947

30 Randazzo, P. A. and Fales, H. M. (2002) Preparation of myristoylated Arf1 and Arf6 proteins. In GTPase Protocols: The Ras Superfamily, Vol. 189 (Manser, E. and Leung, T., eds.), pp. 169-180, Humana, Totowa, NJ

31 Yoon, H. Y., Jacques, K., Nealon, B., Stauffer, S., Premont, R. T. and Randazzo, P. A. (2004) Differences between AGAP1, ASAP1 and Arf GAP1 in substrate recognition: interaction with the N-terminus of Arf1. Cell. Signalling 16, 1033-1044

32 Randazzo, P. A., Terui, T., Sturch, S. and Kahn, R. A. (1994) The amino-terminus of ADP-ribosylation factor (Arf)- 1 is essential for interaction with $\mathrm{G}(\mathrm{s})$ and Arf GTPase-activating protein. J. Biol. Chem. 269, 29490-29494

33 Randazzo, P. A., Miura, K. and Jackson, T. R. (2001) Assay and purification of phosphoinositide-dependent ADP-ribosylation factor (ARF) GTPase activating proteins. Methods Enzymol. 329, 343-354

34 Che, M. M., Boja, E. S., Yoon, H.-Y., Gruschus, J., Jaffe, H., Stauffer, S., Schuck, P., Fales, H. M. and Randazzo, P. A. (2005) Regulation of ASAP1 by phospholipids is dependent on the interface between the PH and Arf GAP domains. Cell. Signalling 17, 1276-1288

35 Kam, J. L., Miura, K., Jackson, T. R., Gruschus, J., Roller, P., Stauffer, S., Clark, J., Aneja, R. and Randazzo, P. A. (2000) Phosphoinositide-dependent activation of the ADP-ribosylation factor GTPase-activating protein ASAP1 - evidence for the pleckstrin homology domain functioning as an allosteric site. J. Biol. Chem. $\mathbf{2 7 5}$ 9653-9663

36 Pace, C. N., Vajdos, F., Fee, L., Grimsley, G. and Gray, T. (1995) How to measure and predict the molar absorption-coefficient of a protein. Protein Sci. 4, 2411-2423

37 Scheffzek, K., Ahmadian, M. R. and Wittinghofer, A. (1998) GTPase-activating proteins: helping hands to complement an active site. Trends Biochem. Sci. 23, 257-262

38 Ahmadian, M. R., Hoffmann, U., Goody, R. S. and Wittinghofer, A. (1997) Individual rate constants for the interaction of Ras proteins with GTPase-activating proteins determined by fluorescence spectroscopy. Biochemistry 36, 4535-4541

39 Gideon, P., John, J., Frech, M., Lautwein, A., Clark, R., Scheffler, J. E. and Wittinghofer, A. (1992) Mutational and kinetic analyses of the GTPase-activating protein (GAP)-P21 interaction - the C-terminal domain of GAP is not sufficient for full activity. Mol. Cell. Biol. 12, 2050-2056

40 Graham, D. L., Eccleston, J. F. and Lowe, P. N. (1999) The conserved arginine in Rho-GTPase-activating protein is essential for efficient catalysis but not for complex formation with Rho • GDP and aluminum fluoride. Biochemistry 38, 985-991

41 Nixon, A. E., Brune, M., Lowe, P. N. and Webb, M. R. (1995) Kinetics of inorganic-phosphate release during the interaction of P21Ras with the GTPase-activating proteins, P120-Gap and neurofibromin. Biochemistry 34, 15592-15598

42 Zhang, B. L. and Zheng, Y. (1998) Regulation of RhoA GTP hydrolysis by the GTPase-activating proteins p190, p50RhoGAP, Bcr, and 3BP-1. Biochemistry $\mathbf{3 7}$ 5249-5257

43 Rittinger, K., Walker, P. A., Eccleston, J. F., Smerdon, S. J. and Gamblin, S. J. (1997) Structure at 1.65 angstrom of RhoA and its GTPase-activating protein in complex with a transition-state analogue. Nature 389, 758-762

44 Mittal, R., Ahmadian, M. R., Goody, R. S. and Wittinghofer, A. (1996) Formation of a transition-state analog of the Ras GTPase reaction by Ras - GDP, tetrafluoroaluminate, and GTPase-activating proteins. Science $\mathbf{2 7 3}, 115-117$

45 Vetter, I. R. and Wittinghofer, A. (2001) Signal transduction - the guanine nucleotidebinding switch in three dimensions. Science 294, 1299-1304 